OPEN ACCESS

Edited by:

Jacqueline Grima-Pettenati, Centre National de la Recherche

Scientifique, France

Reviewed by:

Rosa M. Cusido,

University of Barcelona, Spain

Brigitte Chabbert,

French National Institute for

Agricultural Research, France

*Correspondence:

Teemu H. Teer

teemu.teeri@helsinki.fi

${ }^{\dagger}$ Present Address:

Anna Kärkönen,

Green Technology, Natural Resources Institute Finland (Luke), Helsinki,

Finland;

Liisa Kaarina Simola Ritarikatu 9 B, 00170 Helsinki, Finland

Specialty section:

This article was submitted to Plant Metabolism and Chemodiversity,

a section of the journal

Frontiers in Plant Science

Received: 22 June 2016

Accepted: 27 September 2016

Published: 18 October 2016

Citation:

Warinowski T, Koutaniemi S, Kärkönen A, Sundberg I, Toikka M, Simola LK, Kilpeläinen I and Teeri TH

(2016) Peroxidases Bound to the Growing Lignin Polymer Produce Natural Like Extracellular Lignin in a

Cell Culture of Norway Spruce.

Front. Plant Sci. 7:1523

doi: 10.3389/fpls.2016.01523

\section{Peroxidases Bound to the Growing Lignin Polymer Produce Natural Like Extracellular Lignin in a Cell Culture of Norway Spruce}

\author{
Tino Warinowski ${ }^{1}$, Sanna Koutaniemi ${ }^{2}$, Anna Kärkönen ${ }^{1 \dagger}$, Ilari Sundberg ${ }^{1}$, Merja Toikka ${ }^{3}$, \\ Liisa Kaarina Simola ${ }^{4 t}$, Ilkka Kilpeläinen ${ }^{3}$ and Teemu H. Teeri ${ }^{\text {* }}$ \\ 'Department of Agricultural Sciences, Viikki Plant Science Centre, University of Helsinki, Finland, ${ }^{2}$ Department of Food and \\ Environmental Chemistry, University of Helsinki, Finland, ${ }^{3}$ Laboratory of Organic Chemistry, Department of Chemistry, \\ University of Helsinki, Finland, ${ }^{4}$ Department of Biosciences, University of Helsinki, Finland
}

Lignin, an important component of plant cell walls, is a polymer of monolignols derived from the phenylpropanoid pathway. Monolignols are oxidized in the cell wall by oxidative enzymes (peroxidases and/or laccases) to radicals, which then couple with the growing lignin polymer. We have investigated the characteristics of the polymerization reaction by producing lignin polymers in vitro using different oxidative enzymes and analyzing the structures formed with NMR. The ability of the enzymes to oxidize high-molecular-weight compounds was tested using cytochrome $c$ as a substrate. The results support an idea that lignin structure is largely determined by the concentration ratios of the monolignol (coniferyl alcohol) and polymer radicals involved in the coupling reaction. High rate of the lignin polymer oxidation compared to monolignol oxidation leads to a naturallike structure. The high relative rate can be achieved by an open active site of the oxidative enzyme, close proximity of the enzyme with the polymeric substrate or simply by high enzymatic activity that consumes monolignols rapidly. Monolignols, which are oxidized efficiently, can be seen as competitive inhibitors of polymer oxidation. Our results indicate that, at least in a Norway spruce (Picea abies L. Karst.) cell culture, a group of apoplastic, polymer-oxidizing peroxidases bind to the lignin polymer and are responsible for production of natural-like lignin in cell suspension cultures in vivo, and also in vitro. The peroxidases bound to the extracellular lignin had the highest ability to bind to various cell wall polymers in vitro. Extracellular lignin contains pectin-type sugars, making them possible attachment points for these cationic peroxidases.

\footnotetext{
Keywords: dehydrogenation polymer, lignin-carbohydrate complex, lignin polymerization, oxidative enzymes, peroxidase, polymer oxidation
}

\section{INTRODUCTION}

Lignin is a complex, hydrophobic component in the plant cell wall of water-conducting vessels and tracheids, as well as support-giving sclerenchyma cells. It gives cell walls resilience against both mechanical stress and biological perils, and contributes to the calorific value of wood as a fuel. However, for pulp and paper manufacture as well as in biofuel production lignin is an 
<smiles>COc1cc(/C=C/CO)ccc1O</smiles><smiles>OC/C=C/c1ccc(O)cc1</smiles><smiles>[R]c1cc(OC)c2c(c1)-c1cc([R])cc(OC)c1OC(C(O)O)C(c1ccc([R20])c(OC)c1)O2</smiles><smiles>[R]Oc1ccc(C(O)C([Z])Oc2ccc([R])cc2OC)cc1OC</smiles><smiles>[R20]c1cc(OC)c2c(c1)[C@@H](CO)[C@@H](c1ccc([R20])c(OC)c1)O2</smiles>

FIGURE 1 | The structures of spruce lignin monomers coniferyl alcohol (A) and $p$-coumaryl alcohol (B), as well as four principal substructures in softwood lignin: 5-5-O-4 (C), $\beta-0-4(D), \beta-5(E)$, and $\beta-\beta(F)$. R denotes a continuing lignin molecule, or a hydrogen atom, if the molecule ends at that point. Similarly, R' denotes either a continuing lignin molecule or a phenylpropanoid side chain.

obstruction that needs to be removed or broken down in processes that are both economically and environmentally challenging. Some lignin structures are more susceptible to degradation than others. Achieving control of lignin content as well as subunit and linkage composition would thus create significant benefits (Grabber, 2005).

Lignin is a polymer of monolignols, which are derivatives of the phenylpropanoid pathway. The principal monolignol in gymnosperms is coniferyl alcohol, supplemented with a small quantity of $p$-coumaryl alcohol (Figure 1; Boerjan et al., 2003). Monolignols are oxidized in the apoplast into resonance-stabilized radicals by the action of oxidative enzymes, which can be either peroxidases (class III; EC 1.11.1.7; donor:hydrogen peroxide oxidoreductase) or laccases ( $p$-diphenol:oxygen oxidoreductase, EC 1.10.3.2). The radicals then couple in muro to form the lignin polymer (reviewed by Vanholme et al., 2010; Wang et al., 2013). Both peroxidases and

Abbreviations: DHP, dehydrogenation polymer; HRP, horseradish peroxidase; $\mathrm{pI}$, isoelectric point; PMSF, phenylmethylsulfonyl fluoride. laccases are present in the apoplast as numerous isoenzymes with wide substrate specificities (Koutaniemi et al., 2005, 2015; Berthet et al., 2011; Turlapati et al., 2011; Novo-Uzal et al., 2013; Barros et al., 2015). It is now known that both laccases and peroxidases contribute to lignin biosynthesis at least in Arabidopsis (Arabidopsis thaliana; Berthet et al., 2011; NovoUzal et al., 2013; Zhao et al., 2013; Shigeto and Tsutsumi, 2016).

Monolignol radicals can couple in various ways to create different substructures in lignin, which, in principle, leads to a random structure in lignin. The four main substructures are $\beta$ $O-4, \beta-5, \beta-\beta$ and 5-5-O-4 (dibenzodioxocin) linkages (Figure 1; Adler, 1977; Karhunen et al., 1995). However, it has been shown that the relative abundances of these substructures vary in different parts of the cell wall. For example, in Norway spruce (Picea abies (L.) Karst.), the 5-5-O-4 structure is enriched in the innermost part of the tracheid secondary cell wall (Kukkola et al., 2003). The parameters which determine the abundance of lignin substructures have been under active evaluation. The classical (combinatorial) model of lignin polymerization states that the structure of the polymer is determined by the chemistry 
of the coupling reaction, where proteins play no role beyond production of phenolic radicals. Polymerization would thus be a stochastic process (Ralph et al., 2004). The alternative hypothesis about dirigent protein-mediated coupling of monolignols in lignin formation (Gang et al., 1999; Davin and Lewis, 2005) has not been supported by scientific data, although a recent paper suggests that dirigent proteins have a role in lignin formation in the Casparian strip of root endodermis (Hosmani et al., 2013). Factors already shown to affect the types of bonds created include concentration of monolignols (Adler, 1977; Terashima et al., 1995; Syrjänen and Brunow, 2000) and pH (Ämmälahti and Brunow, 2000). Moreover, the carbohydrate matrix of the cell wall has been suggested to influence the structure of lignin, as spherical lignin particles were detected in the middle lamella within the random pectin network, whereas lamellar lignin particles were detected in the secondary cell wall that contains uniformly oriented cellulose microfibrils (Donaldson, 1994; Wi et al., 2005).

Formation of a covalent bond between a monolignol and the growing lignin polymer requires the presence of an unpaired electron in both entities, meaning that also the polymer must be oxidized during the process. In natural lignin, growth of the polymer takes place in an end-wise manner, i.e., monolignols are sequentially added to the polymer (Brunow et al., 1998). Oxidation of the polymer may happen by a radical transfer between the monolignol radical and the polymer, but this mechanism has been shown to be inefficient (Sasaki et al., 2004). Also, a shuttle mechanism over the plasma membrane involving, for example, manganese ions that would oxidase monolignols/lignin polymer in the apoplast has been suggested (Ōnnerud et al., 2002). Alternatively, the enzymes may oxidize lignin directly. It has been shown that poplar (Populus alba) has a cell wall-bound peroxidase capable of directly oxidizing high-molecular-weight lignin polymers (Sasaki et al., 2004). In vitro this enzyme produces from monolignols and hydrogen peroxide a dehydrogenation polymer (DHP), which has structural similarities with natural lignins. The ability of peroxidases to oxidize lignin directly was concluded to be important in the production of natural lignin polymers (Sasaki et al., 2004). As such, the 5-5-O-4 substructures are indicative of lignin polymer oxidation, since these substructures are not found in lignin oligomers and are found at reduced amounts in in vitro-produced DHPs (Ralph, 1999).

In this study, we have used a Norway spruce tissue culture as a model system, as the cells produce extracellular lignin in the culture medium (Simola et al., 1992; Kärkönen et al., 2002; Koutaniemi et al., 2007; Kärkönen and Koutaniemi, 2010). Structurally, this polymer resembles natural lignins (Brunow et al., 1990, 1993, 1998; Koutaniemi et al., 2005). A high number of peroxidase isoenzymes and one laccase are present in the culture medium (Kärkönen et al., 2002; Koutaniemi et al., 2015), resembling in this sense the developing xylem of Norway spruce (Fagerstedt et al., 2010). Interestingly, a specific subset of cationic peroxidases and another laccase isoenzyme are bound to the extracellular lignin (Koutaniemi, 2007; Koutaniemi et al., 2015). Purified culture medium laccase and peroxidases have a high affinity to coniferyl alcohol and are able to form high-molecular-weight DHP from coniferyl alcohol in vitro (Kärkönen et al., 2002; Koutaniemi et al., 2005, 2015). In the present work, we have used oxidative enzymes isolated from the culture medium and from the extracellular lignin to produce DHPs for structural studies. Fungal laccases from lignindegrading fungi Trametes hirsuta and Melanocarpus albomyces were also utilized as these enzymes are known to be able to oxidize polymeric lignin (Kiiskinen et al., 2002; Rittstieg et al., 2002). As pectin-type sugars were detected to be bound to extracellular lignin, we assessed binding of the enzymes extracted from the extracellular lignin and other sources to cell wall components and polymers resembling them. We suggest that the extracellular lignin-bound fraction of the secreted suspension culture peroxidases is specialized in lignin polymerization and, more generally, that the concentration ratio of polymer and monomer radicals is a key factor that determines lignin structure.

\section{MATERIALS AND METHODS}

\section{Tissue Culturing and Enzyme Harvesting}

The Norway spruce tissue culture line A3/85, which forms extracellular lignin in the culture medium (Simola et al., 1992), was maintained and propagated on a solid nutrient medium and transferred to liquid medium for lignin production (Kärkönen et al., 2002; Koutaniemi et al., 2005). Extracellular lignin was collected by centrifugation and the soluble enzymes from the culture medium were harvested by concentrating the medium by ultrafiltration.

Prior to protein extraction, extracellular lignin was washed several times with water until no peroxidase activity was released. The polymer-bound proteins were extracted twice ( $1 \mathrm{~h}$ each, at $+4^{\circ} \mathrm{C}$, with slow mixing) with $20 \mathrm{mM}$ MESbuffer, $\mathrm{pH} 6.5$ supplemented with $1 \mathrm{M} \mathrm{NaCl}, 1 \mathrm{mM} \mathrm{CaCl}$, and $1 \mathrm{mM}$ phenylmethylsulfonyl fluoride (PMSF). Proteins were concentrated by ultrafiltration (Pall Stirred Cell Omega 10K system) and excess salt was removed using a PD-10 desalting column (GE Healthcare) equilibrated with the same buffer except that $\mathrm{NaCl}$ concentration was $50 \mathrm{mM}$. The extracted proteins were separated in an isoelectric focusing gel and stained for peroxidase

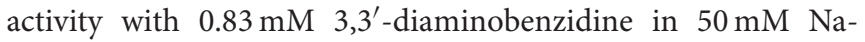
citrate buffer, pH 5.0 containing $10 \mathrm{mM} \mathrm{CaCl}_{2}$ and $0.5 \mathrm{mM} \mathrm{H}_{2} \mathrm{O}_{2}$ (Kärkönen et al., 2002).

\section{Purification of Extracellular Lignin-Bound Peroxidases and Isolating the Corresponding cDNA Molecules}

During protein purification, peroxidase activity in the fractions was screened on a microplate format using $0.67 \mathrm{mM}$ ABTS (2,2-azino-bis(3-ethylbenzothiazoline-6-sulfonic acid), SigmaAldrich) and $0.4 \mathrm{mM} \mathrm{H}_{2} \mathrm{O}_{2}$ in $50 \mathrm{mM} \mathrm{Na}$-acetate buffer, $\mathrm{pH}$ 5.0, with detection at $412 \mathrm{~nm}$ in a Multiscan MCC/340 plate reader (Labsystems). The peroxidase fraction was partially purified essentially as described in Koutaniemi et al. (2005). Briefly, the extracted protein fraction was brought to $2 \mathrm{M}$ ammonium sulfate concentration and centrifuged at $10,000 \times \mathrm{g}$ for $20 \mathrm{~min}$. The soluble fraction was loaded into a Phenyl Sepharose 6 FF column 
(GE Healthcare) equilibrated with $20 \mathrm{mM}$ MES pH 6.0, $2 \mathrm{M}$ ammonium sulfate and $1 \mathrm{mM} \mathrm{CaCl}_{2}$. Proteins were eluted with a step gradient to the same buffer without ammonium sulfate. Fractions containing peroxidase activity were loaded onto a Concanavalin A Sepharose column (GE Healthcare) equilibrated with $20 \mathrm{mM}$ MES pH 6.0, $1 \mathrm{M}$ ammonium sulfate, $1 \mathrm{mM} \mathrm{CaCl}_{2}$, $\mathrm{MnCl}_{2}$ and $\mathrm{MgCl}_{2}$ each and eluted with $500 \mathrm{mM}$ methyl $\alpha$-Dmannopyranoside (Fluka) in the same buffer. Eluted proteins were concentrated with a Omega 10K Stirred Cell System (Pall Life Sciences) and loaded into a Superdex 75 size exclusion chromatography column equilibrated with $20 \mathrm{mM}$ MES pH 6.0, $50 \mathrm{mM} \mathrm{NaCl}, 1 \mathrm{mM} \mathrm{CaCl} 2$. Peroxidases from the size exclusion step were loaded into a SP Sepharose High Performance cation exchange column (GE Healthcare) equilibrated with $20 \mathrm{mM}$ MES $\mathrm{pH}$ 6.0, $50 \mathrm{mM} \mathrm{NaCl}, 1 \mathrm{mM} \mathrm{CaCl}$. Basic peroxidases were eluted with a linear gradient to $300 \mathrm{mM} \mathrm{NaCl}$ in the same buffer and concentrated as above.

The pool of basic peroxidases was separated in a 10\% SDSPAGE gel. Proteins in the $32-42 \mathrm{kDa}$ range were excised from the gel, subjected to in-gel digestion with trypsin and alkylated. The tryptic fragments were sequenced with LC-MS/MS tandem mass spectrometry as described in Poutanen et al. (2001).

Degenerate primers ( $5^{\prime}$-GGWGTCGTGTCRTGTGCWGAC ATTCTC-3' 5' $^{\prime}$-CTCATCTCAMTITTTCARGCTCA-3', 5' -CTG GTRCTGTAGGAYTCAAC-3') were designed based on obtained peptide sequences (CADIL, LISLFQAQ, VESYSTSTHAFFK) showing similarity to peroxidases. Total and mRNA were isolated from the tissue-cultured spruce cells and reverse transcribed to cDNA as described in Koutaniemi et al. (2005). Partial peroxidase cDNA sequences were amplified with a polymerase chain reaction using the degenerate primers. Rapid amplification of cDNA ends ( $3^{\prime}$ RACE) was done using oligo-dT as the $3^{\prime}$ primer. Full-length $5^{\prime}$ RACEs were performed with SMART RACE cDNA Amplification Kit (BD Biosciences Clontech). Gene specific reverse primers were designed based on the $5^{\prime}$ untranslated regions of the genes and used in $3^{\prime}$ RACE (BD Biosciences Clontech) to obtain the full-length sequences. Three full-length cDNAs, each coding for a few sequenced peptides, were recovered. Primers used for cloning are shown in Supplementary Table 1.

\section{Production of DHP}

Two different enzyme samples from the Norway spruce tissue culture were used in the DHP synthesis, total soluble proteins from the culture medium and extracted lignin-bound proteins (Table 1). In addition, DHP was produced with horseradish peroxidase (HRP) and lignin-degrading fungal laccases from $T$. hirsuta and M. albomyces (Table 1). Both hydrogen peroxide $(34 \mathrm{mM}, 5 \mathrm{ml})$ and coniferyl alcohol (Fluka, $34 \mathrm{mM}, 5 \mathrm{ml}$ ) were simultaneously injected at a constant rate $\left(250 \mu \mathrm{h} \mathrm{h}^{-1}\right)$ using a micro pump (Harvard Apparatus) during a $20 \mathrm{~h}$-period into $5 \mathrm{ml}$ of enzyme solution containing a certain amount of coniferyl alcohol-oxidizing activity (Table 3 for activity amounts) in a stirred flask at room temperature. After injection, the reaction was allowed to proceed for additional $4 \mathrm{~h}$. With laccases, the hydrogen peroxide was omitted and replaced with the buffer. Polymers were collected by centrifugation $(2500 \mathrm{~g}, 15 \mathrm{~min})$,
TABLE 1 | Peroxidase and laccase samples used in this study.

\begin{tabular}{lll}
\hline Abbreviation & Description & Source/references \\
\hline Pa-SL & $\begin{array}{l}\text { Picea abies total soluble culture } \\
\text { medium proteins }\end{array}$ & Kärkönen et al., 2002 \\
Pa-BD & $\begin{array}{l}\text { Picea abies total proteins that } \\
\text { bind the extracellular lignin }\end{array}$ & $\begin{array}{l}\text { Koutaniemi, 2007; this } \\
\text { study }\end{array}$ \\
HRP & Horseradish peroxidase type II & $\begin{array}{l}\text { Sigma-Aldrich } \\
\text { MP-11 }\end{array}$ \\
Mal LAC & Microperoxidase & Sigma-Aldrich \\
Thi LAC & laccase & Kiiskinen et al., 2002 \\
\hline
\end{tabular}

washed three times with water and lyophilized. All reactions were performed in $50 \mathrm{mM}$ sodium acetate, $\mathrm{pH}$ 5.0, supplemented with $2.5 \mathrm{mM} \mathrm{CaCl}_{2}$. $\mathrm{pH} 5.0$ was chosen to approximate the $\mathrm{pH}$ of the spruce cell cultures during extracellular lignin formation $(\mathrm{pH}$ 4.2-4.8; Kärkönen et al., 2002) and, on the other hand, the $\mathrm{pH}$ optimum of the isolated and total culture medium peroxidases (pH 4.0-6.5; Koutaniemi et al., 2005, and unpublished data). As $\mathrm{pH}$ affects the structure of DHPs produced (Ämmälahti and Brunow, 2000), DHP production by HRP was also conducted at pH 5.0.

\section{Structural Analysis of DHPs and Lignin}

Milled wood lignin (MWL) was prepared according to Björkman (1956) with some modifications. Sawdust was first extracted in a Soxhlet apparatus with acetone $(48 \mathrm{~h})$ and acetone-water 9:1 $(4 \mathrm{~h})$, then dried under vacuum. Dry sawdust was milled in a ball mill (Fritsch Pulverisette 6) at $320 \mathrm{rpm}$ for $50 \mathrm{~h}$ and the wood powder was extracted with dioxane-water 9:1 (2h) in a cooled ultrasonic bath. Dioxane-water was evaporated with a rotavapor nearly to the dryness, glacial acetic acid was added and the mixture was stirred at $+50^{\circ} \mathrm{C}$ for $2 \mathrm{~h}$. The filtered acetic acid solution was poured into water whereupon lignin precipitated. The precipitated lignin was collected by centrifugation, washed 1-2 times with water and dried.

For NMR analyses MWL, isolated extracellular lignin and DHPs were acetylated. In a typical procedure, the lignin sample (5-50 mg) was suspended into $10 \mathrm{ml}$ of acetanhydride/pyridine $(1: 1, \mathrm{v} / \mathrm{v})$. After stirring for $12 \mathrm{~h}$ at room temperature under argon, an excess of ethanol was added and the solvent was evaporated in a rotavapor. Successive ethanol addition and evaporation steps were performed until all residual pyridine, acetic acid and ethyl acetate were removed from the sample. The dry, acetylated lignin was dissolved into $0.7 \mathrm{ml}$ of $\mathrm{CDCl}_{3}$ or deuterated DMSO (Cambridge Isotope Laboratories). The NMR spectra were measured with Varian Unity Inova 600 spectrometer $\left({ }^{1} \mathrm{H}\right.$ frequency $\left.600 \mathrm{MHz}\right)$. A modified version of Q-HSQC (Heikkinen et al., 2003), QQ-HSQC (Koskela et al., 2005) was applied to obtain quantitative $2 \mathrm{D}$ NMR spectra. The spectral width was $6000 \mathrm{~Hz}$ in ${ }^{1} \mathrm{H}$ and $15,000 \mathrm{~Hz}$ in ${ }^{13} \mathrm{C}$. The number of scans was 256 (1024 data points) and the number of time increments 128 (hypercomplex method) with a repetition rate of $3 \mathrm{~s}$, yielding measurement time of $\sim 52 \mathrm{~h}$ for each spectrum. The spectra were zero-filled to $2048 * 1024$ 
data points and apodized with squared bell window functions in both dimensions prior to Fourier transformation. All spectra were processed and analyzed with the standard VNMR software (Agilent Technologies). The relative amounts of the main structural units of lignin samples were calculated as percentage values from the sum of integral values of $\beta-O-4, \beta-5, \beta-\beta$ and 5-5-O-4 substructures (Heikkinen et al., 2003). In order to give equal weight to the different bond types that occur in the polymer, standard scores were calculated. For each bond type, the standard score $\mathbf{z}$ has average value of 0 and variance of 1 across the samples.

\section{Enzyme Activity Measurements}

Coniferyl alcohol peroxidase was determined at $262 \mathrm{~nm}$ with $100 \mu \mathrm{M}$ coniferyl alcohol (Fluka) and $250 \mu \mathrm{M} \mathrm{H}_{2} \mathrm{O}_{2}$ in $45 \mathrm{mM}$ Na-citrate buffer, pH 5.0 (Kärkönen et al., 2002). Coniferyl alcohol oxidase activity was measured at $262 \mathrm{~nm}$ using $70 \mu \mathrm{M}$ coniferyl alcohol in $45 \mathrm{mM} \mathrm{Na}$-acetate buffer, $\mathrm{pH}$ 4.5, supplemented with $125 \mathrm{U} \mathrm{ml}^{-1}$ catalase (Sigma C-100). Measurements were done in triplicate, and $\varepsilon$ of $14,000 \mathrm{M}^{-1}$ $\mathrm{cm}^{-1}$ for coniferyl alcohol was used for quantitative calculations (Kärkönen et al., 2002).

The ability of peroxidases to oxidize a high-molecular-weight substrate, cytochrome $c$ from bovine heart (Sigma-Aldrich), was measured by following a decrease in the absorbance of the reduced ferrocytochrome $c$ at $550 \mathrm{~nm}\left(\varepsilon=18,500 \mathrm{M}^{-1} \mathrm{~cm}^{-1}\right.$; Hodges and Leonard, 1974; Sasaki et al., 2004). First, cytochrome $c$ was reduced with $10 \mathrm{mM} \mathrm{Na}$-dithionite for $30 \mathrm{~min}$. Dithionite was removed by passing the sample through a PD-10 column (GE Healthcare) equilibrated with degassed $50 \mathrm{mM} \mathrm{Na}$-citrate buffer, $\mathrm{pH}$ 5.0. Oxidation of cytochrome $c$ was measured in the same buffer at room temperature using $40 \mu \mathrm{M}$ cytochrome $c$ and 1.2-4.6 nkat coniferyl alcohol peroxidase activity (soluble culture medium and lignin-bound proteins) or $10 \mu \mathrm{g} \mathrm{HRP} \mathrm{(} \sim 5500 \mathrm{nkat}$ coniferyl alcohol peroxidase activity). Non-enzymatic oxidation was first followed for a few minutes, and peroxidase action was started with addition of $50 \mu \mathrm{M} \mathrm{H}_{2} \mathrm{O}_{2}$. The rate of non-enzymatic oxidation was subtracted from the peroxidase-catalyzed reaction. Results were normalized by calculating the ratio of cytochrome $c$ peroxidase activity to coniferyl alcohol peroxidase activity (CytCprx/CAprx). Microperoxidase (MP-11, Sigma-Aldrich), which contains a heme of cytochrome $c$ molecule with amino acids 11-21 still attached, was used as a positive control (34 nkat coniferyl alcohol peroxidase activity / reaction), as it represents an enzyme with a wide-open active site capable of accommodating high-molecular-weight substrates.

The ability of the M. albomyces and T. hirsuta laccases to oxidize DHP produced with HRP (see below) was determined by measuring changes in oxygen concentration with the Oxygraph oxygen electrode (Hansatech Instruments). The measurements were done in an air-saturated $50 \mathrm{mM} \mathrm{Na}$-acetate buffer, $\mathrm{pH}$ 5.0, supplemented with $2.5 \mathrm{mM} \mathrm{CaCl}_{2}$, to which a fixed amount of laccase (1.2 nkat coniferyl alcohol oxidase activity) and $1 \mathrm{mg}$ of suspended DHP were added (total volume $1 \mathrm{ml}$ ). The measuring cell was kept under magnetic stirring to prevent sedimentation of the polymer.

\section{Enzyme Binding Assays}

Binding assays were performed to study the ability of peroxidases and laccases to bind to lignin and to lignin-like polymers (MWL, extracellular lignin, deglycosylated extracellular lignin and DHP produced with HRP), or to anionic polysaccharides (polygalacturonic acid and alginate). The tested enzyme samples included total soluble proteins from the culture medium, extracted lignin-bound proteins and HRP, as well as fungal laccases from $M$. albomyces and T. hirsuta. Control reactions contained the equal amount of enzymes without any polymer, and were treated similarly to the samples. Binding assays were conducted at $\mathrm{pH} 4.5$ to approximate the $\mathrm{pH}$ of the culture medium during the formation of extracellular lignin.

The enzyme sample (2.5 nkat of coniferyl alcohol (per)oxidase activity) was diluted with the binding buffer $(50 \mathrm{mM}$ sodium tartrate, $\mathrm{pH} 4.5,50 \mathrm{mM} \mathrm{NaCl}, 4 \mathrm{mM} \mathrm{CaCl}, 1 \mathrm{mM}$ PMSF, $0.01 \%(\mathrm{w} / \mathrm{v}) \mathrm{BSA}$ ) to a volume of $0.8 \mathrm{ml}$. Polymer $(15-50 \mathrm{mg}$ depending on availability; however, as polysaccharides form a large gel-volume when mixed with $\mathrm{Ca}^{2+}$ ions, a lower amount of polysaccharide polymers was used) was added and the sample was incubated for $2 \mathrm{~h}$ at $+6^{\circ} \mathrm{C}$ with a slow mixing. After centrifugation $(21,000 \mathrm{~g}, 4 \mathrm{~min})$ the pellet was washed five times with the binding buffer, and the polymer-bound enzymes were eluted by extracting twice with $0.7 \mathrm{ml}$ of the extraction buffer (20 mM MES, pH 6.0, $1 \mathrm{M} \mathrm{NaCl}, 4 \mathrm{mM} \mathrm{CaCl}, 1 \mathrm{mM}$ PMSF, $0.01 \% \mathrm{BSA})$. The extractions were performed in conditions similar to binding with a 1 -h incubation and the extracts were pooled together. Coniferyl alcohol (per)oxidase activities were measured from the supernatant after the binding (unbound activity) and the extraction steps (bound activity).

The polymers for binding assays were prepared as follows: extracellular lignin was harvested from the suspension culture by centrifugation, washed briefly with water and then 5 times with the extraction buffer (see above) to remove the native, lignin-bound proteins. After washing twice with water, lignin was lyophilized and ground to a fine powder in a mortar. This extracellular lignin sample was further deglycosylated by treating the polymer $(250 \mathrm{mg}$ suspended in $50 \mathrm{mM} \mathrm{Na}$ acetate, $\mathrm{pH}$ 5.0) with a mixture of several glycosyl hydrolases (described in Virkki et al., 2008) at $37^{\circ} \mathrm{C}$ for $48 \mathrm{~h}$. At $24 \mathrm{~h}, 5 \mathrm{mg}$ of pectolyase (Sigma-Aldrich) was added to the reaction to increase the degradation of pectic polysaccharides. After hydrolysis, enzymes were inactivated by boiling for $5 \mathrm{~min}$ and the extracellular lignin was washed twice with water, twice with $1 \mathrm{M} \mathrm{NaCl}$, and finally three times with water. The extracellular lignin control was treated similarly except that the enzymes were replaced with buffer only. DHP and MWL were washed, lyophilized and ground to a fine powder in a mortar similarly to the extracellular lignin sample.

\section{Determination of the Carbohydrate Component of Extracellular Lignin}

Extracellular lignin was washed with water and then extracted with acetone to remove low-molecular-weight phenolic compounds, lyophilized and further dried in a vacuum oven at 
$40^{\circ} \mathrm{C}$ for $1 \mathrm{~h}$. The sample ( $5 \mathrm{mg}$; in duplicates from three separate tissue cultures) was degraded by acid methanolysis essentially as described in Sundberg et al. (1996). Released monosaccharides were trimethylsilylated before gas chromatographic separation, which was performed on HP 6890N GC equipped with a flame ionization detector (Agilent Technologies) using a DB-1 ( $30 \mathrm{~m}, 0.25 \mathrm{~mm}$ i.d., $0.25 \mu \mathrm{m}$ film thickness) capillary column from Agilent Technologies. Oven temperature profile was as follows: $150^{\circ} \mathrm{C}$ for $3 \mathrm{~min} ;+1^{\circ} \mathrm{C} / \mathrm{min}$ until $155^{\circ} \mathrm{C}$; hold for $1 \mathrm{~min}$; $+2^{\circ} \mathrm{C} / \mathrm{min}$ until $200^{\circ} \mathrm{C}$; $+20^{\circ} \mathrm{C} / \mathrm{min}$ until $325^{\circ} \mathrm{C}$. Arabinose, xylose, rhamnose, glucuronic acid, galacturonic acid, mannose, galactose and glucose were used as standards and sorbitol as an internal standard for quantification.

\section{RESULTS}

\section{Cloning of cDNA Molecules Encoding Extracellular Lignin-Bound Peroxidases}

The Norway spruce tissue culture used in our study secretes proteins into the culture medium; part of these are bound to the extracellular lignin and can be extracted with a buffer containing $1 \mathrm{M} \mathrm{NaCl}$. An isoelectric focusing gel stained for peroxidase activity showed that some of the extracted proteins with an isoelectric point $(\mathrm{pI}) \sim 10$ had peroxidase activity (Koutaniemi, 2007). These peroxidases were partially purified, and amino acid sequences for several internal peptides were determined using LC-MS/MS tandem mass spectrometry (Supplementary Table 2). Based on the sequence data, cDNA molecules encoding the peptides were isolated. Three full length cDNAs were obtained, each coding for a few distinct amino acid sequences obtained during peptide sequencing (Supplementary Figure 1). The three cDNA sequences were designated as PaPx16, PaPx17, and PaPx18 (EMBL: AM293546, AM293547, and AM293548, respectively). $P a P x 16$ and $P a P x 17$ are both translated into 341 amino acids. They are close homologs, the encoded amino acid sequence differing at eight positions. The PaPx18 cDNA codes for a polypeptide of 310 amino acids. All three cDNAs encode a predicted signal sequence. The predicted pIs for mature PaPx16, PaPx17, and PaPx18 are 9.1, 9.2, and 8.4, respectively. The lower pI compared with the one determined from an isoelectric focusing gel is probably due to the bound $\mathrm{Ca}^{2+}$ ions and the heme, which increase the $\mathrm{pI}$ of the correctly folded peroxidase by up to 2 pI units (Welinder et al., 2002)

We searched the corresponding sequences from the Norway spruce genome (Nystedt et al., 2013). The closest homolog for PaPx16 and PaPx17 is MA_3486g0010, and for PaPx18 MA_10432379g0020. Both of the genes have some expression in early wood (phloem+cambium+xylem; Nystedt et al., 2013).

\section{Peroxidase and Laccase Isoenzymes Differ in Polymer Oxidation}

Formation of radicals on lignin oligo- and polymers is a prerequisite for the polymer growth. Therefore, peroxidases that are involved in lignin polymerization should also be able to oxidize polymeric lignin. DHP produced from coniferyl alcohol with HRP was prepared as a near-authentic substrate, but
TABLE 2 | Oxidation of cytochrome $c$ by peroxidases (CytC prx) or dehydrogenation polymer (DHP) by laccases as a percentage of oxidation of coniferyl alcohol using soluble culture medium peroxidases (Pa-SL), lignin-bound peroxidases (Pa-BD), horseradish peroxidase (HRP), microperoxidase (MP), T. hirsuta laccase (Thi LAC) and M. albomyces laccase (Mal LAC); $n=3$.

\begin{tabular}{lcc}
\hline Protein sample & $\begin{array}{c}\text { CytC prx oxidation (\% of } \\
\text { coniferyl alcohol oxidation) }\end{array}$ & $\begin{array}{c}\text { DHP oxidation (\% of } \\
\text { coniferyl alcohol oxidation) }\end{array}$ \\
\hline Pa-SL & $1.8 \pm 0.2$ & \\
Pa-BD & $0.19 \pm 0.05$ & \\
HRP & $0.018 \pm 0.002$ & \\
MP & $35.5 \pm 1.5$ & $64.9 \pm 5.5$ \\
Thi LAC & & $13.8 \pm 1.6$ \\
Mal LAC & & \\
\hline
\end{tabular}

we could not reliably apply the UV-Vis spectroscopic method of Sasaki et al. (2004) due to a limited amount of enzyme at hand. Instead, we used cytochrome $c$ as a proxy highmolecular-weight substrate for peroxidases (Sasaki et al., 2004). We compared the ability of soluble culture medium proteins, extracted lignin-bound proteins and HRP to oxidize cytochrome c. Microperoxidase consisting of a heme with 11 amino acids attached was used as a positive control, and it was the most efficient of all tested enzymes in cytochrome $c$ oxidation, reaching up to $35 \%$ of the oxidation rate for coniferyl alcohol (Table 2). Out of spruce native peroxidases, soluble culture medium peroxidases showed the highest oxidation rate, $1.8 \%$ of the rate for coniferyl alcohol. This was ca. 10-fold higher than that for extracted lignin-bound peroxidases, which was again 10-fold higher than that for HRP (Table 2).

With laccases, assessment of DHP oxidation was possible by measuring oxygen consumption. Of the two laccases studied here, the rate of DHP oxidation for T. hirsuta laccase was ca. 5 times higher than for the $M$. albomyces laccase when compared with the rate of coniferyl alcohol oxidation (Table 2).

\section{Polymer-Oxidizing Enzymes Produce Natural-Like Lignin In Vitro}

To study the structural similarity of DHPs synthesized with various peroxidases and laccases, the distribution of the bond types in the resulting polymers were determined by quantitative 2D NMR. Standard scores were calculated for each result in order to give an equal weight to each bond type, and Pearson correlation coefficients were calculated to the bond distribution obtained for Norway spruce MWL (Table 3). The Pearson correlation coefficient provides a single measure, ranging from -1 to 1 , that describes the similarity of the DHP to MWL.

As lignin is a heterogeneous polymer that is composed of different structural units, its structure can be described using the percentage values of different monomer unit linkages (Table 3). MWL contained a high proportion of $\beta-O-4$ (66.7\%) and of 5-5$O-4$ substructures $(6.5 \%)$, corresponding well with earlier results (Heikkinen et al., 2003). Extracellular lignin had an equally high proportion of 5-5-O-4 while the content of $\beta-O-4$ was slightly lower. The DHP produced with 200 nkat (measured as 
TABLE 3 | Structural composition of natural and synthetic lignin samples determined using Q-HSQC and QQ-HSQC.

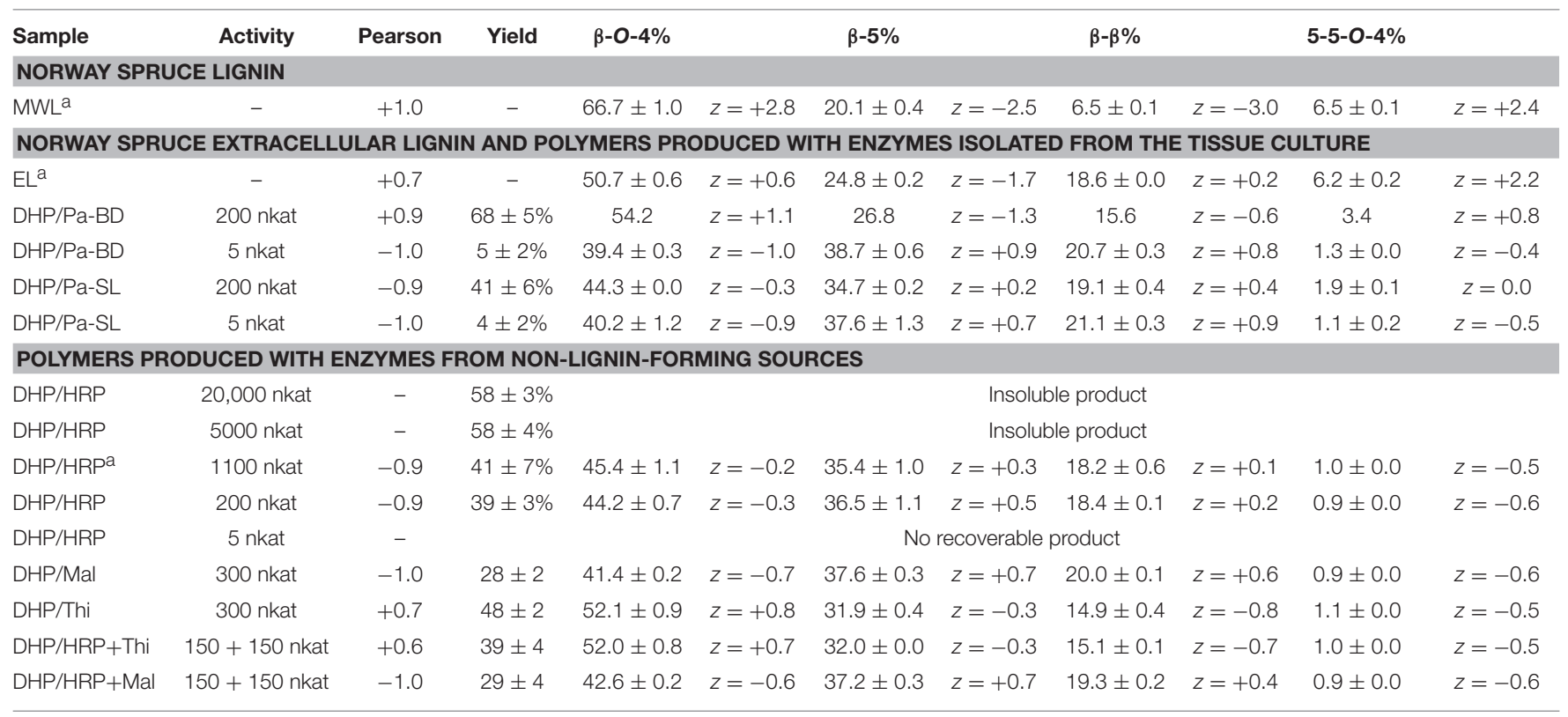

Activity column indicates the total coniferyl alcohol (per)oxidase activity used in the production of DHPs. Pearson column gives a Pearson correlation of the standard scores of a sample with milled wood lignin (MWL). Yield column gives the yields of DHP synthesis as a percentage of the maximum theoretical yield. The final four columns give the proportions of the four main lignin substructures $(\beta-O-4, \beta-5, \beta-\beta$ and $5-5-O-4)$ as percentages of the total $2 D$ NMR signal from these structures and standard scores (z) calculated from these values. EL, extracellular lignin; DHP, dehydrogenation polymer; $\mathrm{Pa}-\mathrm{BD}$, total proteins extracted from extracellular lignin; Pa-SL, total soluble proteins from the culture medium; HRP, horseradish peroxidase; Mal, Melanocarpus albomyces laccase; Thi, Trametes hirsuta laccase.

${ }^{a}$ Results published previously in Koutaniemi et al. (2005).

coniferyl alcohol peroxidase activity) of enzymes extracted from the extracellular lignin resembled MWL more than any other DHP, and gave the highest yield of the polymer (Table 3). Very high activity (5000 and 20,000 nkat) of HRP produced good yields of the polymer, but these DHPs were resistant to dissolution for NMR, possibly indicating crosslinking reactions taking place. The soluble culture medium enzymes (200 nkat) produced DHPs that were structurally different from the MWL samples, containing less $\beta-O-5$ and 5-5-O-4 linkages (Table 3). A similar result was obtained with HRP (200 nkat) and lower activities (5 nkat) of the extracellular lignin-extracted enzymes. The second best structural correlation with MWL after the DHP produced with the extracellular lignin-extracted enzymes (at 200 nkat) was observed in DHP produced using T. hirsuta laccase (Table 3) with the ability to oxidize lignin polymers efficiently (Table 2). Interestingly, the DHP produced with T. hirsuta laccase was more similar to MWL than that produced with $M$. albomyces laccase, the enzyme with a lower polymer-oxidizing activity. DHPs produced with mixtures of equal amounts of each laccase and HRP (150 nkat each) showed that the T. hirsuta laccase dominated over HRP the structure of the resulting polymer. With HRP and M. albomyces laccase the polymer was similar to those produced with either enzyme alone.

\section{Extracellular Lignin Contains Pectic Polysaccharides}

NMR analyses of extracellular lignin have shown the presence of carbohydrates (I. Kilpeläinen, unpublished data). These ligninassociated carbohydrates remained bound to lignin after washing with buffered salt solution ( $1 \mathrm{M} \mathrm{NaCl})$, suggesting the presence of covalent linkages between the sugar units and lignin. The carbohydrate component of the extracellular lignin was studied in more detail using gas chromatography after degradation of the carbohydrate component by acid methanolysis. The total carbohydrate content in the extracellular lignin was 166 $\pm 27 \mu \mathrm{g} / \mathrm{mg}$ dry weight (Table 4). Galacturonic acid (GalA), arabinose (Ara) and galactose (Gal) were detected in larger amounts, while rhamnose (Rha), xylose (Xyl), glucose (Glc) and mannose (Man) were present at lower levels. The abundance of GalA suggests the presence of pectic polysaccharides, mainly homogalacturonan (Albersheim et al., 2011; Atmodjo et al., 2013). However, the presence of Rha, Ara and Gal also point to the presence of rhamnogalacturonan $\mathrm{I}$, which contains a backbone of repeating $\alpha$-GalA-(1-2)- $\alpha$-L-Rha-(1-4) disaccharide, which is substituted with side chains containing mostly Ara and Gal (Atmodjo et al., 2013). The detected Man and Glc suggest the presence of (galacto)glucomannan, which is the main hemicellulosic polysaccharide in softwoods (Rowell et al., 2005).

\section{Extracellular Lignin-Extracted Peroxidases Bind to Lignin-like Polymers}

To determine which component of the extracellular lignin the peroxidases are bound to, we studied the ability of the total soluble culture medium proteins and the total proteins extracted from the extracellular lignin to bind different phenolic and carbohydrate polymers. The polymers included extracellular lignin before and after enzymatic degradation of the carbohydrate component, DHP produced from coniferyl 
TABLE 4 | Sugar composition of the carbohydrate fraction of the extracellular lignin, determined after acid methanolysis and trimethylsilylation using gas chromatography (average \pm standard error of the mean, $n=5$ ).

\begin{tabular}{lc}
\hline Monosaccharide & $\boldsymbol{\mu g} \mathbf{~ ( m g ~ d r y ~ w e i g h t ) ~}^{-\mathbf{1}}$ \\
\hline Galacturonic acid & $60.1 \pm 7.6$ \\
Arabinose & $57.4 \pm 7.8$ \\
Galactose & $32.3 \pm 5.2$ \\
Glucose & $5.3 \pm 1.6$ \\
Rhamnose & $3.9 \pm 0.6$ \\
Mannose & $2.1 \pm 0.8$ \\
Xylose & $1.7 \pm 0.4$ \\
Fucose & $1.5 \pm 0.3$ \\
Glucuronic acid & $0.9 \pm 0.5$ \\
\hline
\end{tabular}

alcohol with HRP, MWL and two anionic carbohydrate polymers, calcium polygalacturonate and calcium alginate.

Cationic peroxidases extracted from the extracellular lignin had a significant affinity to all lignin polymers tested (Figure 2). The binding was greatest to extracellular lignin itself, with 55 $\pm 3 \%$ of the activity bound, but significant binding was also observed to all other polymers tested, with binding between 17 and 29\%. Enzymatic degradation of the extracellular ligninbound carbohydrates reduced, but did not eliminate this binding (Figure 2). In contrast, the binding of the soluble culture medium peroxidases to the polymers was limited. The highest apparent affinity was to calcium alginate, which bound $5 \pm 0.5 \%$ of the soluble peroxidase activity (Figure 2). Only basic peroxidases from the culture medium bound to lignin as shown in the IEF gel stained for peroxidase activity (Figure 3).

The ability of $T$. hirsuta laccase, $M$. albomyces laccase and HRP to bind to the DHP produced by HRP was also measured. Under the experimental conditions $8.0 \pm 1.1 \%$ of the T. hirsuta laccase activity and $3.8 \pm 3.1 \%$ of that of $M$. albomyces were bound to the polymer. No significant binding of HPR could be detected (data not shown).

\section{DISCUSSION}

In this work we have investigated the role of oxidative enzymes, isolated from Norway spruce, on lignin structure with the help of DHPs produced from coniferyl alcohol. The results show that different enzymes, or varying enzyme activity amounts under otherwise identical conditions, produce phenolic polymers with different proportions of the lignin substructures.

Lignin polymer grows when an unpaired electron in the polymer radical forms a covalent bond with an unpaired electron in the monolignol radical. Thus, all enzymes that can produce a polymer from monolignols must also oxidize the polymeric substrate (directly or indirectly). However, only high oxidation rate of the polymer will produce intramolecular cross-links, such as the 5-5 bond that occurs in the 5-5-O-4 substructure typical for conifer wood (Karhunen et al., 1995; Kukkola et al., 2003). This suggests that the failure of most in vitro-polymers to
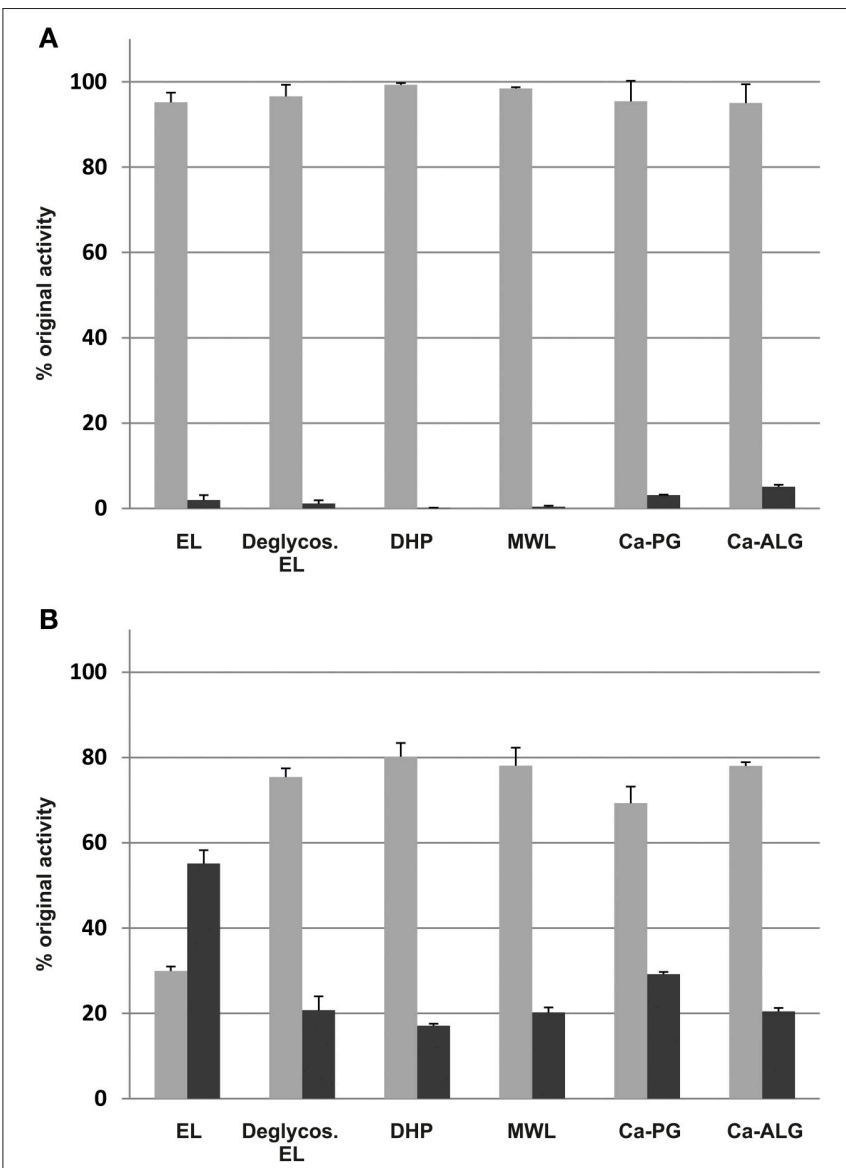

FIGURE 2 | Binding of the soluble culture medium proteins (A), and the extracted, lignin-bound proteins $(B)$ to lignin-like and anionic polysaccharide polymers. EL, extracellular lignin; Deglycos. EL, extracellular lignin after the glycosyl hydrolase treatment; DHP, dehydrogenation polymer from coniferyl alcohol made with HRP; MWL, milled wood lignin; Ca-PG, Ca-polygalacturonate; Ca-ALG, Ca-alginate. Light gray, unbound fraction; dark gray, bound fraction.

mimic natural lignins results from an insufficient oxidation of the growing polymer.

The present study shows that the Norway spruce cell suspension culture has a subset of peroxidases, which can bind to lignin-like and pectic polymers (Figures 2, 3), and which can oxidize polymeric lignin (Table 3). This set of extracellular lignin-extracted peroxidases, as well as $T$. hirsuta laccase that also has a considerable polymer-oxidizing ability (Table 2 ), produced DHPs in a high yield $(>50 \%)$ and with a high proportion of $\beta-O-4$ substructures (Table 3). This is considered as a signature for end-wise polymerization (Sarkanen, 1971), requiring oxidation of the polymer to proceed. Enzymes such as HRP or M. albomyces laccase with lower polymer-oxidizing ability (Table 2), when dosed at the same level, produced a condensed polymer with less $\beta-O-4$ and a high proportion of $\beta-5$ linkages (Table 3). Interestingly, DHP produced with the extracellular lignin-extracted enzymes (at 200 nkat) was close to natural spruce lignin (MWL), more similar than any of the DHPs 


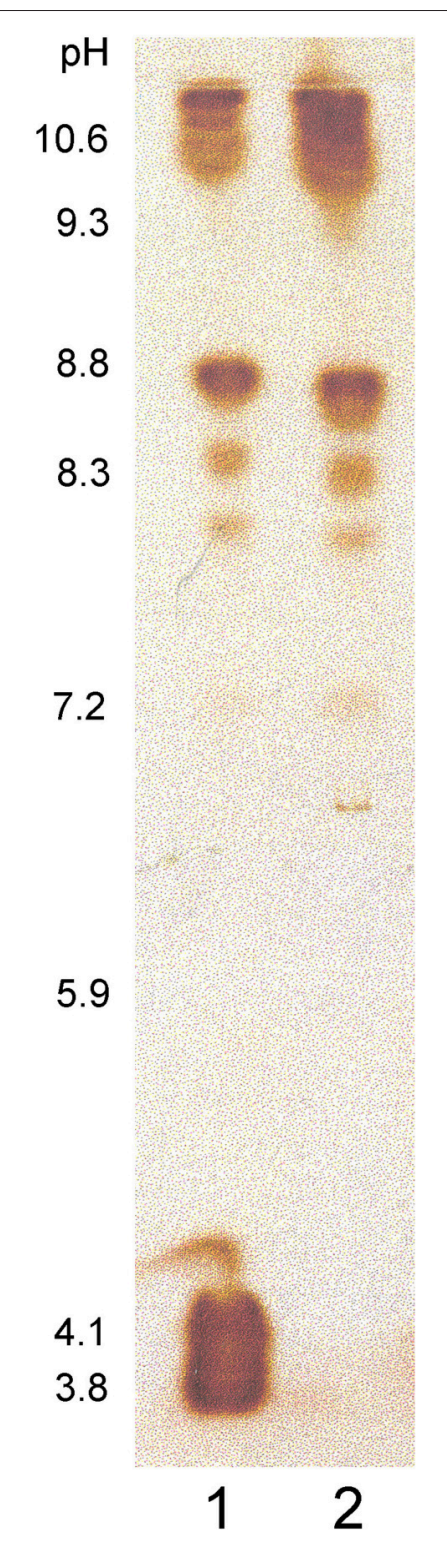

FIGURE 3 | Norway spruce culture medium proteins separated in an isoelectric focusing gel and stained for peroxidase activity. (1) Proteins unbound to MWL, (2) Proteins bound to MWL. Numbers beside the IEF gel indicate the determined $\mathrm{pH}$ gradient in the gel.

produced with other enzymes tested. The main contributor to this similarity was, in addition to the $\beta-O-4$ content, the relatively high content of 5-5-O-4 bonds (Table 3 ). With a more sparing amount of the lignin-extracted enzymes (5 nkat) we obtained a low polymer yield and a bond distribution similar to that in DHP produced with HRP at a 200-nkat dosage (Table 3).

This observation led to a suggestion that the key factor in the synthesis of natural-like lignin is not the polymer-oxidizing ability per se, but instead, the ratio of polymer to monomer oxidation occurring in the actual reaction. One way to increase polymer oxidation is to have enzymes that are specialized in this function; however, also an increase in the enzyme activity should have the same effect since it leads to a rapid consumption of the monomers. Therefore, also HRP should be able to produce a natural-like lignin if sufficient amount of the activity was applied. Indeed, experiments with 5000 nkat and 20,000 nkat of HRP did produce a precipitate in a high yield (58\%, Table 3). Contrary to most of the DHPs assayed, but similar to some repetitions of the experiment with 200 nkat of the extracellular lignin-extracted enzymes, these polymers could not be made soluble for the NMR analysis of the actual bond distributions, which is a possible indicator of crosslinking of the polymer.

Increasing the oxidative enzymatic activity to produce more natural-like lignins is essentially the same but an extended effect, which is known from comparisons of "zutropf" and "zulauf" polymers, where "zutropf" polymers have a higher molecular mass and a structure that is more similar to that in natural lignins (Freudenberg, 1956). Zutropf refers to gradual feeding of the substrates into the reaction vessel, i.e., increasing the enzyme to substrate ratio (somewhat simulating lignin biosynthesis), while in a zulauf reaction all substrates are added in the beginning of the reaction. Syrjänen and Brunow (2000) utilized the same principle in an elegant experimental setup, where coniferyl alcohol was provided very slowly to a HRPcontaining solution through a dialysis membrane, producing a native-like polymer with increased proportion of 5-5-O-4 bonds. Méchin et al. (2007) have also tested how peroxidase activity affects the DHP structure, concluding however that for zutropf polymers the structure was more natural-like when lower enzyme activities were used. This seemingly contradictory result is at least partly due to a different measure of "naturallike", which for Méchin et al. (2007) was the abundance of $\beta-O-4$ bonds. In the present study, we used ratios of all four bond types, with 5-5-O-4 having a high weight. As stated above, this bond type forms only when the growing polymer is oxidized efficiently. In fact, high redox potential of the guaiacyl groups prevents their cross-coupling until the concentration of the more reactive coniferyl alcohol monomers is sufficiently low and approaches zero (Brunow et al., 1998). In xylem cells the concentration of monolignols approaches zero after programmed cell death of lignifying cells. Indeed, in spruce this is accompanied by an increase in 5-5-O-4 structures in the S3 layer of the secondary cell wall (Kukkola et al., 2003).

Our results are in line with the view that lignin polymerization is a stochastic process where the probabilities of various bond types are determined by the concentration ratios, resonance structures and oxidation potentials of the radicals involved (Adler, 1977; Grabber et al., 1996; Syrjänen and Brunow, 1998, 2000; Sasaki et al., 2004, 2008). As the latter two are essentially constant, the concentration ratio of polymer to monomer radicals emerges as a principal way how lignin structure is determined. Oxidative enzymes differ in their ability to accept large substrates. In poplar, one of the secreted, cell wall-bound peroxidases showed increased polymer-oxidizing activity that related to tyrosine residues that relay electrons to the surface of the enzyme (Sasaki et al., 2008; Shigeto et al., 2012), a similar solution as in fungal enzymes that oxidatively degrade lignin 
(Ruiz-Dueñas and Martínez, 2009). In the spruce tissue culture, those peroxidases that produced the natural-lignin-like polymer also efficiently bound to the substrate, i.e., to extracellular lignin (Figure 2). This binding may be partly via electrostatic interactions to negatively charged pectic polysaccharides that are attached to extracellular lignin (Table 4). As the glycosyl hydrolase treatment only partially suppressed the re-binding of the enzymes to deglycosylated extracellular lignin (Figure 2), some direct interaction with lignin seems likely. This is supported by the fact that peroxidases extracted from the extracellular lignin bound also to DHP produced with HRP in the absence of carbohydrates. Interestingly, DHPs produced in the presence of pectin or xylan form covalently bound lignin-carbohydrate complexes, increasing the molar mass and solubility of the DHPs, as well as the content of $\beta-O-4$ structures using zutropf feeding of the reactants (Cathala and Monties, 2001; Barakat et al., 2007; Li et al., 2015). This emphasizes the role of the polysaccharide matrix on the outcome of lignin polymerization also in vivo.

It is too early to say if the results of Sasaki et al. (2008) and the experiments described here represent angiosperm and gymnosperm solutions for lignin polymerization, but they suggest that among plant peroxidases, some have evolved and specialized in the task of lignin polymerization. According to the emerging insight, plants have five principal ways to control lignin structure: The ratio of different monolignols synthesized, the rate of transport of monolignols into the apoplast, $\mathrm{pH}$ of the apoplast and the quantity and the properties of the oxidative enzymes. These simple parameters may be sufficient to control

\section{REFERENCES}

Adler, E. (1977). Lignin chemistry: past, present and future. Wood Sci. Technol. 11, 169-218. doi: 10.1007/BF00365615

Albersheim, P., Darvill, A., Robersts, K., Sederoff, R., and Staehelin, A. (2011). Plant Cell Walls. From Chemistry to Biology. (New York, NY: Garland Science, Taylor \& Francis Group), 430.

Ämmälahti, E., and Brunow, G. (2000). Use of $\beta-{ }^{13} \mathrm{C}$ labelled coniferyl alcohol to detect "end-wise" polymerization in the formation of DHPs. Holzforschung 54, 604-608. doi: 10.1515/HF.2000.102

Atmodjo, M. A., Hao, Z., and Mohnen, D. (2013). Evolving views of pectin biosynthesis. Annu. Rev. Plant Biol. 64, 747-779. doi: 10.1146/annurev-arplant042811-105534

Barakat, A., Winter, H., Rondeau-Mouro, C., Saake, B., Chabbert, B., and Cathala, B. (2007). Studies on xylan interactions and cross-linking to synthetic lignins formed by bulk and end-wise polymerization: a model study of lignin carbohydrate complex formation. Planta 26, 267-281. doi: 10.1007/s00425007-0479-1

Barros, J., Serk, H., Granlund, I., and Pesquet, E. (2015). The cell biology of lignification in higher plants. Ann. Bot. 7, 1050-1074. doi: 10.1093/aob/m cr046

Berthet, S., Demont-Caulet, N., Pollet, B., Bidzinski, P., Cézard, L., Le Bris, P., et al. (2011). Disruption of LACCASE4 and 17 results in tissue-specific alterations to lignification of Arabidopsis thaliana stems. Plant Cell 23, 1124-1137. doi: $10.1105 /$ tpc. 110.082792

Björkman, A. (1956). Finely divided wood. I. Extraction of lignin with neutral solvents. Svensk Papperstidning 59, 477-485.

Boerjan, W., Ralph, J., and Baucher, M. (2003). Lignin biosynthesis. Annu. Rev. Plant Biol. 54, 519-546. doi: 10.1146/annurev.arplant.54.031902.134938 the variation in lignin that can be observed in both gymnosperm and angiosperm wood.

\section{AUTHOR CONTRIBUTIONS}

TT, IK, LS, SK, AK, and TW conceived and designed the experiments. TW, SK, AK, IS, MT, IK, and TT performed the research. TW, SK, AK, and TT wrote the manuscript. All authors read and approved the manuscript.

\section{ACKNOWLEDGMENTS}

This work was funded by Tekes, the Finnish Funding Agency for Technology and Innovation (to TT) and the Finnish Graduate School in Plant Biology (to TW). AK thanks Academy of Finland for funding (grant 251390). We thank Professor Kristiina Kruus (VTT) for donating laccase samples and Professor Maija Tenkanen (Univ. of Helsinki) for the use of her laboratory facilities. Maaret Mustonen and Marja Huovila are acknowledged for their invaluable technical assistance. We also thank Tuija Niinimäki, Marjo Kilpinen, Sami Holmström, and Teresa Laitinen for the help in subculturing spruce cells.

\section{SUPPLEMENTARY MATERIAL}

The Supplementary Material for this article can be found online at: http://journal.frontiersin.org/article/10.3389/fpls.2016. 01523

Brunow, G., Ede, R. M., Simola, L. K., and Lemmetyinen, J. (1990). Lignins released from Picea abies suspension cultures-true native spruce lignins? Phytochemistry 29, 2535-2538. doi: 10.1016/0031-9422(90)85183-G

Brunow, G., Kilpeläinen, I., Lapierre, C., Lundquist, K., Simola, L. K., and Lemmetyinen, J. (1993). The chemical structure of extracellular lignin released by cultures of Picea abies. Phytochemistry 32, 845-850. doi: 10.1016/00319422(93)85218-G

Brunow, G., Kilpeläinen, I., Sipilä, J., Syrjänen, K., Karhunen, P., Setälä, H., et al. (1998). "Oxidative coupling of phenols and the biosynthesis of lignin," in Lignin and Lignan Biosynthesis, eds N. G. Lewis and S. Sarkanen (Washington, DC: American Chemical Society). Chapter 10, 131-147.

Cathala, B., and Monties, B. (2001). Influence of pectins on the solubility and the molar mass distribution of dehydrogenation polymers (DHPs, lignin model compounds). Int. J. Biol. Macromol. 29, 45-51. doi: 10.1016/S01418130(01)00145-3

Davin, L. B., and Lewis, N. G. (2005). Lignin primary structures and dirigent sites. Curr. Opin. Biotechnol. 16, 407-415. doi: 10.1016/j.copbio.2005.06.011

Donaldson, L. A. (1994). Mechanical constrains on lignin deposition during lignification. Wood Sci. Technol. 28, 111-118. doi: 10.1007/BF00192690

Fagerstedt, K. V., Kukkola, E. M., Koistinen, V. V. T., Takahashi, J., and Marjamaa, K. (2010). Cell wall lignin is polymerised by class III secretable plant peroxidases in Norway spruce. J. Integr. Plant Biol. 52, 186-194. doi: 10.1111/j.1744-7909.2010.00928.x

Freudenberg, K. (1956). Beiträge zur Erforschung des Lignins. Angew. Chem. 61, 508-512. doi: 10.1002/ange.19560681603

Gang, D. R., Costa, M. A., Fujita, M., Dinkova-Kostova, A. T., Wang, H. B., Burlat, V., et al. (1999). Regiochemical control of monolignol radical coupling: a new paradigm for lignin and lignan biosynthesis. Chem. Biol. 6, 143-151. doi: 10.1016/S1074-5521(99)89006-1 
Grabber, J. H. (2005). How do lignin composition, structure, and cross-linking affect degradability? A review of cell wall model studies. Crop Sci. 45, 820-831. doi: 10.2135/cropsci2004.0191

Grabber, J. H., Ralph, J., Hatfield, R. D., Quideau, S., Kuster, T., and Pell, A. N. (1996). Dehydrogenation polymer-cell wall complexes as a model for lignified grass walls. J. Agric. Food Chem. 44, 1453-1459. doi: 10.1021/jf9502717

Heikkinen, S., Toikka, M. M., Karhunen, P. T., and Kilpeläinen, I. A. (2003). Quantitative 2D HSQC (Q-HSQC) via suppression of J-dependence of polarization transfer in NMR spectroscopy: application to wood lignin. J. Am. Chem. Soc. 125, 4362-4367. doi: 10.1021/ja029035k

Hodges, T. K., and Leonard, R. T. (1974). Purification of a plasma-membrane bound adenosine triphosphatase from plant roots. Methods Enzymol. 32, 392-406. doi: 10.1016/0076-6879(74)32039-3

Hosmani, P. S., Kamiya, T., Danku, J., Naseer, S., Geldner, N., Guerinot, M. L., et al. (2013). Dirigent domain-containing protein is part of the machinery required for formation of the lignin-based Casparian strip in the root. Proc. Natl. Aacd. Sci. U.S.A. 110, 14498-14503. doi: 10.1073/pnas.1308412110

Karhunen, P., Rummakko, P., Sipilä, J., and Brunow, G. (1995). The formation of dibenzodioxocin structures by oxidative coupling. A model reaction for lignin biosynthesis. Tetrahedron Lett. 36, 4501-4504. doi: 10.1016/00404039(95)00769-9

Kärkönen, A., and Koutaniemi, S. (2010). Lignin biosynthesis studies in plant tissue cultures. J. Integr. Plant Biol. 52, 176-185. doi: 10.1111/j.17447909.2010.00913.x

Kärkönen, A., Koutaniemi, S., Mustonen, M., Syrjänen, K., Brunow, G., Kilpeläinen, I., et al. (2002). Lignification related enzymes in Picea abies suspension cultures. Physiol. Plant 114, 343-353. doi: 10.1034/j.13993054.2002.1140303.x

Kiiskinen, L. L., Viikari, L., and Kruus, K. (2002). Purification and characterization of a novel laccase from the ascomycete Melanocarpus albomyces. Appl. Microbiol. Biotechnol. 59, 198-204. doi: 10.1007/s00253-002-1012-x

Koskela, H., Kilpeläinen, I., and Heikkinen, S. (2005). Some aspects of quantitative 2D NMR. J. Magn. Reson. 174, 237-244. doi: 10.1016/j.jmr.2005.02.002

Koutaniemi, S. (2007). Lignin Biosynthesis in Norway Spruce: From A Model System to the Tree. Ph.D. dissertation, University of Helsinki. Available online at: http://urn.fi/URN:ISBN:978-952-10-4292-8

Koutaniemi, S., Malmberg, H. A. M., Simola, L. K., Teeri, T. H., and Kärkönen, A. (2015). Norway spruce (Picea abies) laccases; characterisation of a laccase in a lignin-forming tissue culture. J. Integr. Plant Biol. 57, 341-348. doi: 10.1111/jipb. 12333

Koutaniemi, S., Toikka, M. M., Kärkönen, A., Mustonen, M., Lundell, T., Simola, L. K., et al. (2005). Characterization of basic p-coumaryl and coniferyl alcohol peroxidases from a lignin-forming Picea abies suspension culture. Plant Mol. Biol. 58, 141-157. doi: 10.1007/s11103-005-5345-6

Koutaniemi, S., Warinowski, T., Kärkönen, A., Alatalo, E., Fossdal, C. G., Saranpää, P., et al. (2007). Expression profiling of the lignin biosynthetic pathway in Norway spruce using EST sequencing and real-time RT-PCR. Plant Mol. Biol. 65, 211-328. doi: 10.1007/s11103-007-9220-5

Kukkola, E. M., Koutaniemi, S., Gustafsson, M., Karhunen, P., Ruel, K., Lundell, T. K., et al. (2003). Localization of dibenzodioxocin substructures in lignifying Norway spruce xylem by transmission electron microscopy-immunogold labeling. Planta 217, 229-237. doi: 10.1007/s00425-003-0983-x

Li, Q., Koda, K., Yoshinaga, A., Takabe, K., Shimomura, M., Hirai, Y., et al. (2015). Dehydrogenative polymerization of coniferyl alcohol in artificial polysaccharide matrices: effects of xylan on the polymerization. J. Agric. Food Chem. 63, 4613-4620. doi: 10.1021/acs.jafc.5b01070

Méchin, V., Baumberger, S., Pollet, B., and Lapierre, C. (2007). Peroxidase activity can dictate the in vitro lignin dehydrogenative polymer structure. Phytochemistry 68, 571-579. doi: 10.1016/j.phytochem.2006.11.024

Novo-Uzal, E., Fernández-Pérez, F., Herrero, J., Gutiérrez, J., Gómes-Ros, L. V., Bernal, M. Á., et al. (2013). From Zinnia to Arabidopsis; approaching the involvement of peroxidases in lignification. J. Exp. Bot. 64, 3499-3518. doi: $10.1093 / \mathrm{jxb} / \mathrm{ert} 221$

Nystedt, B., Street, N. R., Wetterbom, A., Zuccolo, A., Lin, Y. C., Scofield, D. G., et al. (2013). The Norway spruce genome sequence and conifer genome evolution. Nature 497, 579-584. doi: 10.1038/nature12211
Ōnnerud, H., Zhang, L., Gellerstedt, G., and Henriksson, G. (2002). Polymerization of monolignols by redox shuttle-mediated enzymatic oxidation. Plant Cell 14, 1953-1962. doi: 10.1105/tpc.001487

Poutanen, M., Salusjärvi, L., Ruohonen, L., Penttilä, M., and Kalkkinen, N. (2001). Use of matrix-assisted laser desorption/ionization time-of-flight mass mapping and nanospray liquid chromatography/electrospray ionization tandem mass spectrometry sequence tag analysis for high sensitivity identification of yeast proteins separated by two-dimensional gel electrophoresis. Rapid Commun. Mass Spectrom. 15, 1685-1692. doi: 10.1002/rcm.424

Ralph, J. (1999). Lignin Structure: Recent Developments. Madison, WI: US Dairy Forage Research Center, USDA-Agricultural Research Service.

Ralph, J., Lundquist, K., Brunow, G., Lu, F., Kim, H., Schatz, P. F., et al. (2004). Lignins: natural polymers from oxidative coupling of 4-hydroxyphenyl-propanoids. Phytochem. Rev. 3, 29-60. doi: 10.1023/B:PHYT.0000047809.65444.a4

Rittstieg, K., Suurnakki, A., Suortti, T., Kruus, K., Guebitz, G., and Buchert, J. (2002). Investigations on the laccase-catalyzed polymerization of lignin model compounds using size-exclusion HPLC. Enzyme Microb. Technol. 31, 403-410. doi: 10.1016/S0141-0229(02)00102-3

Rowell, R. M., Pettersen, R., Han, J. S., Rowell, J. S., and Tshabalala, M. A. (2005). "Chapter 3: Cell wall chemistry," in Handbook of Wood Chemistry and wood Composites, ed R. M. Rowell (Boca Raton, FL: CRC Press), 35-74.

Ruiz-Dueñas, F. J., and Martínez, Á. T. (2009). Microbial degradation of lignin: how a bulky recalcitrant polymer is efficiently recycled in nature and how we can take advantage of this. Microb. Biotechnol. 2, 164-177. doi: 10.1111/j.17517915.2008.00078.x

Sarkanen, K. V. (1971). "Precursors and their polymerisation," in Lignins Occurrence, Formation, Structure and Reactions, eds K. V. Sarkanen and C. H. Ludwig (New York, NY: Wiley-Interscience), 95-163.

Sasaki, S., Nishida, T., Tsutsumi, Y., and Kondo, R. (2004). Lignin dehydrogenative polymerization mechanism: a poplar cell wall peroxidase directly oxidizes polymer lignin and produces in vitro dehydrogenative polymer rich in ß-O-4 linkage. FEBS Lett. 526, 197-201. doi: 10.1016/S0014-5793(04)00 224-8

Sasaki, S., Nonaka, D., Wariishi, H., Tsutsumi, Y., and Kondo, R. (2008). Role of Tyr residues on the protein surface of cationic cell-wall-peroxidase (CWPO-C) from poplar: Potential oxidation sites for oxidative polymerization of lignin. Phytochemistry 69, 348-355. doi: 10.1016/j.phytochem.2007.08.020

Shigeto, J., Itoh, Y., Tsutsumi, Y., and Kondo, R. (2012). Identification of Tyr-74 and Tyr-177 as substrate oxidation sites in cationic cell-wall-bound peroxidase (CWPO-C) from Populus alba L. FEBS J. 279, 348-357. doi: 10.1111/j.17424658.2011.08429.x

Shigeto, J., and Tsutsumi, Y. (2016). Diverse functions and reactions of class III peroxidases. New Phytol. 209, 1395-1402. doi: 10.1111/nph.13738

Simola, L. K., Lemmetyinen, J., and Santanen, A. (1992). Lignin release and photomixotrophism in suspension cultures of Picea abies. Physiol. Plant. 84, 374-379. doi: 10.1111/j.1399-3054.1992.tb04678.x

Sundberg, A., Sundberg, K., Lillandt, C., and Holmbom, B. (1996). Determination of hemicelluloses and pectins in wood and pulp fibres by acid methanolysis and gas chromatography. Nordic Pulp Paper Res. J. 11, 216-219. doi: 10.3183/NPPRJ-1996-11-04-p216-219

Syrjänen, K., and Brunow, G. (1998). Oxidative cross coupling of $p$ hydroxycinnamic alcohols with dimeric arylglycerol - aryl ether lignin model compounds: the effect of oxidation potentials. J. Chem. Soc. Perkin Trans. 1, 3425-3429. doi: 10.1039/a805349i

Syrjänen, K., and Brunow, G. (2000). Regioselectivity in lignin biosynthesis: the influence of dimerization and cross-coupling. J. Chem. Soc. Perkin Trans. 1, 183-187. doi: 10.1039/a907919j

Terashima, N., Atalla, R. H., Ralph, S. A., Landucci, L. L., Lapierre, C., and Monties, B. (1995). New preparation of lignin polymer models under conditions that approximate cell wall lignification. Holzforschung 49, 521-527. doi: 10.1515/hfsg.1995.49.6.521

Turlapati, P. V., Kim, K. W., Davin, L. B., and Lewis, N. G. (2011). The laccase multigene family in Arabidopsis thaliana: towards addressing the mystery of their gene functions. Planta 233, 439-470. doi: 10.1007/s00425-0101298-3 
Vanholme, R., Demedts, B., Morreel, K., Ralph, J., and Boerjan, W. (2010). Lignin biosynthesis and structure. Plant Physiol. 153, 895-905. doi: 10.1104/pp.110.155119

Virkki, L., Maina, H. N., Johansson, L., and Tenkanen, M. (2008). New enzymebased method for analysis of water-soluble wheat arabinoxylans. Carbohydr. Res. 343, 521-529. doi: 10.1016/j.carres.2007.10.029

Wang, Y., Chantreau, M., Sibout, R., and Hawkins, S. (2013). Plant cell wall lignification and monolignol metabolism. Front. Plant Sci. 4:220. doi: $10.3389 /$ fpls.2013.00220

Welinder, K. G., Justesen, A. F., Kjaersgård, I. V., Jensen, R. B., Rasmussen, S. K., Jespersen, H. M., et al. (2002). Structural diversity and transcription of class III peroxidases from Arabidopsis thaliana. Eur. J. Biochem. 269, 6063-6081. doi: 10.1046/j.1432-1033.2002.03311.x

Wi, S. G., Singh, A. P., Lee, K. H., and Kim, Y. S. (2005). The pattern of of distribution of pectin, peroxidase and lignin in the middle lamella of secondary xylem fibres in alfalfa (Medicago sativa). Ann. Bot. 95, 863-868. doi: 10.1093/aob/mci092
Zhao, Q., Nakashima, J., Chen, F., Yin, Y., Fu, C., Yun, J., et al. (2013). LACCASE is necessary and nonredundant with PEROXIDASE for lignin polymerization during vascular development in Arabidopsis. Plant Cell 25, 3976-3987. doi: 10.1105/tpc.113.117770

Conflict of Interest Statement: The authors declare that the research was conducted in the absence of any commercial or financial relationships that could be construed as a potential conflict of interest.

Copyright (๑) 2016 Warinowski, Koutaniemi, Kärkönen, Sundberg, Toikka, Simola, Kilpeläinen and Teeri. This is an open-access article distributed under the terms of the Creative Commons Attribution License (CC BY). The use, distribution or reproduction in other forums is permitted, provided the original author(s) or licensor are credited and that the original publication in this journal is cited, in accordance with accepted academic practice. No use, distribution or reproduction is permitted which does not comply with these terms. 